Perspectives

\title{
Research Recommendations to Address Dementia Workforce Development Needs
}

Joan Weiss ${ }^{1,+}, *$, Nina Tumosa ${ }^{1,{ }^{\dagger}}$, Robert Espinoza ${ }^{2,}{ }^{\dagger}$, Elizabeth Bragg ${ }^{3,}{ }^{\dagger}$, Jennifer Craft Morgan ${ }^{4,}$ ${ }^{\dagger}$, Jason D. Flatt ${ }^{5,+}$, Eleanor S. McConnell ${ }^{6,+}$, Grace Whiting ${ }^{7,+}$

1. Bureau of Health Workforce, Health Resources and Services Administration, 5600 Fishers Lane, Rockville, MD, USA; E-Mails: jweiss@hrsa.gov; ntumosa@hrsa.gov

2. PHI, 652 40th Street, \#2F Brooklyn, USA; E-Mail: respinoza@PHInational.org

3. College of Nursing, Xavier University Cincinnati, USA; E-Mail: Bragge@xavier.edu

4. Gerontology Institute, Georgia State University, Atlanta, USA; E-Mail: jmorgan39@gsu.edu

5. School of Public Health, University of Nevada Las Vegas, USA; E-Mail: Jason.Flatt@unlv.edu

6. School of Nursing, Duke University, and Department of Veterans Affairs Geriatric Research, Education and Clinical Center (GRECC) Durham, USA; E-Mail: eleanor.mcconnell@duke.edu

7. National Alliance for Caregiving, 1730 Rhode Island Avenue NW, Suite 812, Washington, DC, USA; E-Mail: grace@caregiving.org

+ These authors contributed equally to this work.

* Correspondence: Joan Weiss; E-Mail: jweiss@hrsa.gov

Academic Editor: Ladislav Volicer

Special Issue: Advanced Dementia: Enjoy It or Avoid It?

\section{OBM Geriatrics}

2021, volume 5, issue 1

doi:10.21926/obm.geriatr.2101162
Received: November 12, 2020

Accepted: March 08, 2021

Published: March 16, 2021

\section{Abstract}

This policy paper presents workforce development recommendations for research, clinical care and public stakeholders as they plan future research activities to strengthen the workforce to support the healthcare and social needs of persons living with dementia and their families and caregivers. To create these recommendations, the 2020 National Research Summit on Care, Services and Supports for Persons with Dementia and Their Caregivers (2020

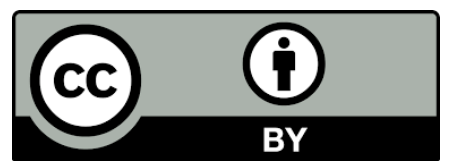


Summit) convened a Workforce Development Stakeholder Workgroup. The Stakeholder Workgroup consisted of an interprofessional team of health professionals from academia, professional organizations, and the federal government with expertise in dementia workforce development. The resulting ten workforce development recommendations represent four themes: (1) Accountability by addressing progress towards implementing the 2017 Research Summit on Care, Services, and Supports for Persons with Dementia and their Caregivers (2017 Summit) workforce recommendations; (2) Improving recruitment, retention, and job quality for direct care workers; (3) Creating a tech-savvy and culturally competent workforce; and (4) Developing educational core competencies, domains and milestones. These recommendations will positively impact the ability of persons living with dementia and their caregivers to access person- and family-centred dementia care that promotes independence and quality of life among those navigating their dementia journey.

\section{Keywords}

Dementia policy; dementia workforce development; core educational competencies; domain and milestones; technology competency; cultural competency; care transitions; recruitment; retention; job quality; accountability; evidence-based practices

\section{Introduction}

In July and August of 2020, the National Institute on Aging (NIA) in the United States (U.S.) convened a three-day on-line Virtual Meeting Series: 2020 National Research Summit on Care, Services and Supports for Persons with Dementia and Their Caregivers (the 2020 Summit). The purpose of the 2020 Summit was to identify and discuss research gaps and opportunities to improve the care, services, and support of persons living with dementia and their caregivers [1]. Multiple stakeholder groups met to identify gaps and opportunities in the year prior to the virtual Summit and sent recommendations to the Summit organizers and presenters for consideration. This paper reflects the in-depth discussion of the recommendations presented by one of the stakeholder groups, the 2020 Workforce Development Workgroup (Workgroup). The Workgroup consisted of an interprofessional team of health professionals from academia, professional organizations, and the federal government with expertise in dementia workforce development. The Workgroup members were chosen for their expertise in, and experience with, dementia.

The first National Research Summit on Care, Services and Supports for Persons with Dementia and Their Caregivers in 2017 (2017 Summit) [2, 3] convened a stakeholder group on workforce development that presented six recommendations addressing four themes: (1) Recruitment and retention of a dementia-capable workforce; (2) Financing and cost of workforce education and training; (3) Interprofessional education and training for care coordination and management of dementia care; and (4) Translation and implementation of effective care. The 2020 Workgroup identified new recommendations, while recognizing the continued value and applicability of the original Workforce Development Workgroup recommendations for 2017 (see Figure 1). Specifically, four new themes were identified from these recommendations: (1) Accountability by evaluating progress towards implementing the 2017 Summit workforce recommendations; (2) Improving 
recruitment, retention, and job quality for direct care workers; (3) Creating a tech-savvy and culturally competent workforce; and (4) Developing educational core competencies, domains and milestones. By addressing these new research recommendations for dementia care workforce development, the tools needed to develop the necessary knowledge and skills should be available to the workforce to provide high-quality dementia care throughout the progression of the disease from the early stages of cognitive impairment through advanced dementia.

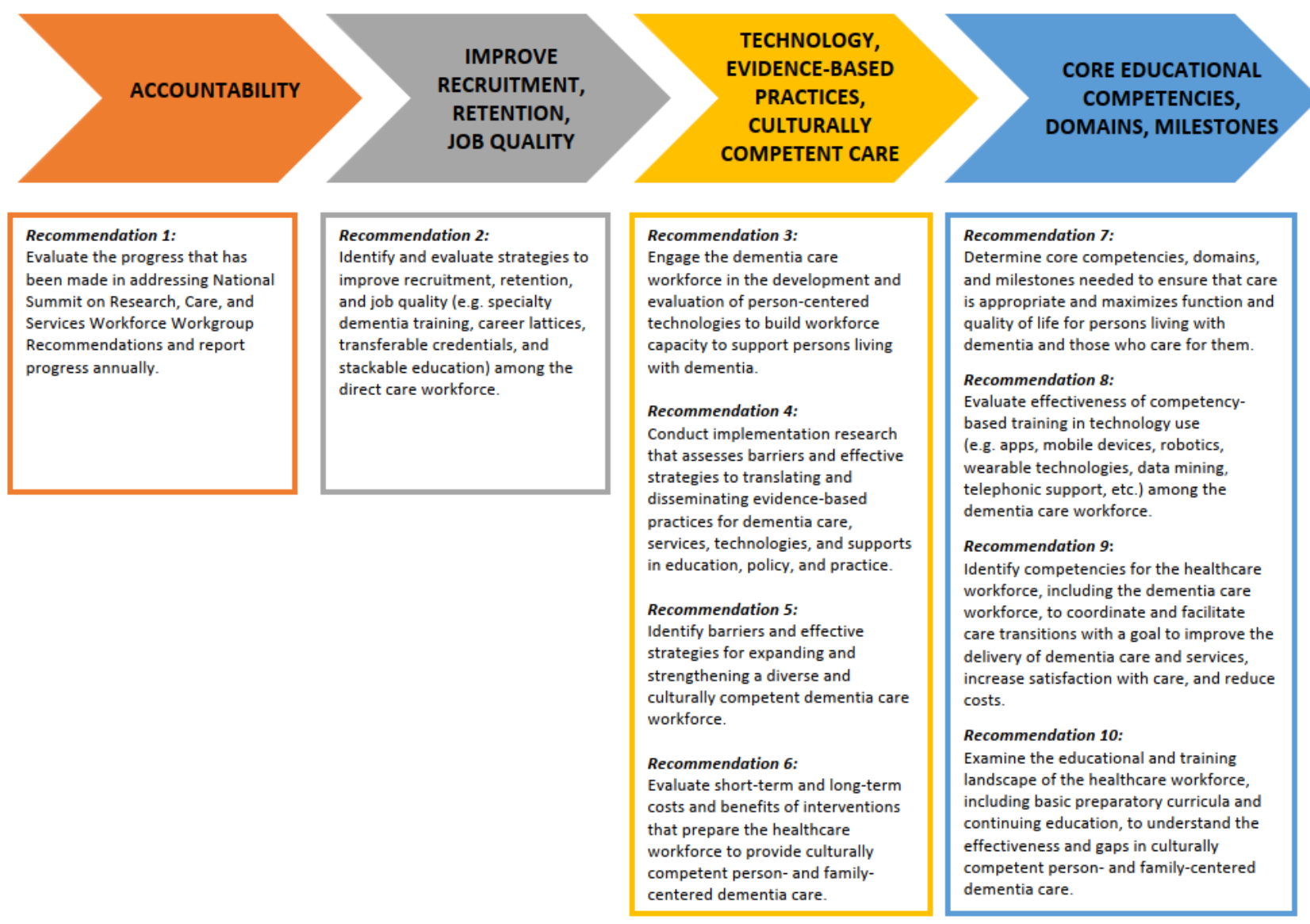

Figure 12020 Summit workforce themes and recommendations.

\section{Materials and Methods}

The creation of this paper did not involve the use of humans, animals, or plant subjects, nor did it involve cell lines.

\subsection{Workgroup Protocols}

\subsubsection{Workgroup Creation}

Three Workgroup Chairs (Weiss, Tumosa and Espinoza) were identified by the Summit Planners. Workgroup Chairs, in collaboration with Summit Planners, selected the remaining Workgroup members from academia, professional organizations, and the federal government. All had expertise in interprofessional dementia workforce development. To ensure diverse sector representation, Workgroup members were chosen from the following professional areas: caregivers (Whiting), health care professionals (Bragg, McConnell and Weiss), neuroscience (Tumosa), paraprofessionals 
(Espinoza), and researchers (Bragg, Craft-Morgan, McConnell, and Flatt). Geographic representation was also taken into consideration. Although no persons living with dementia were included, several Workgroup members are either currently, or have recently been, caregivers of persons living with dementia. All are educators.

\subsubsection{Workgroup Processes}

Summit organizers provided administrative support for the Workgroup for three conference calls that included providing a summary of each call indicating where consensus had been reached and what topics needed further discussion.

The first meeting on September 10, 2019 focused on orienting workgroup members to prior recommendations, and developing a process for retaining those that were still pertinent [2], and identifying new recommendations pertaining to dementia friendly communities, vulnerable populations, and person- and family-centred care. Each Workgroup member was offered the opportunity to suggest a new recommendation or express support for or against recommendations made by other Workgroup members. At the end of the first meeting a total of 9 recommendations were proposed but not finalized. The Workgroup considered how these recommendations might be finalized and whether there were other recommendations to consider.

The second meeting on October 2, 2019, focused on refining prior recommendations by clarifying definitions of caregiver and workforce as follows: caregivers were defined as family members, neighbours, friends, chosen family, and paid caregivers and workforce includes family members and other caregivers of persons living with dementia, including direct care workers, and healthcare students, faculty, and professionals.

The third meeting on October 24, 2019 was devoted to finalizing recommendations. During the development of the recommendations consensus was reached through discussion and sharing of evidence-based practices and research findings. In addition to attending the Workgroup meetings, members also provided input via email. All Workgroup members' views and recommendations were considered during each of the meetings and the final recommendations were unanimously agreed upon.

\subsubsection{Workgroup Next Steps}

The final recommendations were sent to the Summit organizers, who shared them with Summit presenters and the public via the 2020 Summit website [1]. The individual Workgroup recommendations for 2020 can now be found elsewhere [4]. All stakeholder workgroups were encouraged to share their recommendations broadly.

\section{Results}

Each of the 2020 Summit Workgroups were asked by the Summit organizers to generate up to ten research recommendations. The 2020 Summit recommendations created by the Workforce Workgroup are discussed below. In this paper the recommendations are renumbered from the order in which they were originally listed on the 2020 Summit website [4] in order to group them into four themes for discussion and dissemination: (1) evaluating accountability of the 2017 Research Summit on Dementia Care workforce recommendations; (2) improving job quality, 
recruitment, and retention of direct care workers (DCWs); (3) creating a tech-savvy and culturally competent workforce; and (4) developing educational core competencies, domains and milestones. Each theme and its related 2020 Summit recommendations are discussed in this results section.

\subsection{Summit First Theme: Accountability by Evaluating Progress towards Implementing the 2017 National Summit on Research, Care and Services Workforce Workgroup Recommendations}

For the first National Research Summit on Care, Services and Supports for Persons with Dementia and Their Caregivers in 2017 (2017 Summit) [2, 3], six workforce recommendations were proposed. The execution of these recommendations should be the responsibility of academia, health systems, primary care delivery systems, community-based organizations, professional organizations, and federal, state and local agencies. Proposing recommendations designed to move the field forward and improve workforce development is a first step toward developing better jobs for workers who support persons living with dementia. The next step should include tracking progress towards fulfilling these recommendations, as well as acknowledging and addressing challenges and barriers.

2020 Summit Recommendation 1: Evaluate the progress that has been made in addressing the 2017 National Summit on Research, Care and Services Workforce Workgroup recommendations and report progress annually.

The six recommendations made at the 2017 Summit were: (1) Core competency development; (2) Recruitment and retention strategies for expansion of the caregiver workforce; (3) Determining the impact of technology on dementia care; (4) Evaluating the costs and benefits of educating the entire dementia workforce; (5) Developing a workforce competent to provide safe transitional care; and (6) Translate research on dementia care, services and supports into educational models that transform practice and inform policy. Some progress has been made in the past two years, although not for all six of the recommendations. Table 1 summarizes the current status of these 2017 Summit research recommendations.

Table 12017 Summit workforce workgroup recommendations.

2017

Recommendations

Core Competency Development

\section{Progress in Addressing 2017 Summit workforce Recommendations}

Dementia Care Practice Recommendations for quality care practices [5], have been published but little else has been done despite the need for interprofessional competencies in dementia care [6].

Recruitment and Lack of support in the workplace affects retention and turnover [7]. retention strategies Disparities continue in accessing home-based-care-and-services in urban for expansion of the versus rural communities. Infrastructure needs to be addressed in order to caregiver workforce develop an adequate caregiver workforce in rural areas [8]. 
Determining the Technologies serve multiple functions in dementia care [9], and the pace of impact of technology technology development is pushing practice change to promote adoption of on dementia care appropriate technologies [10]. New guidelines have recently been suggested for the development and implementation of new technologies in dementia care [11]. and benefits of educating the entire dementia workforce

Developing a workforce competent to provide safe transitional care
Evaluating the costs

Few studies have been completed on the costs and benefits of targeted dementia care education in the United Kingdom $[12,13]$ and the U.S. $[14$, 15].

Seven evidence-based interventions for care transitions for persons living with dementia have been identified [16]. Additional models include the Aging Brain Care Medical Home [17], the UCLA Alzheimer's and Dementia Care Program [18], and the Partners in Dementia Care [19, 20]. Accreditation standards for programs in undergraduate nursing [21, 22], undergraduate medicine [23], graduate medical education [24], physical therapy [25], occupational therapy [26], social work [27], psychology [28], nutrition [29], physician assistant [30], dental hygiene [31], and pre-doctoral dental education [32] showed that only undergraduate nursing, undergraduate medicine, graduate medical education, occupational therapy and social work have accreditation standards that include care transitions despite the fact that such training improves patient outcomes [33, 34].

Translate research on dementia care, services and supports into educational models that transform practice and inform policy
The age friendly health systems (AFHS) movement [35] does not address training a dementia-specific workforce, but it does promote training the entire workforce on mentation, with a curriculum of four central tenets (the $4 \mathrm{Ms}$ ) of the curriculum (what matters, medication, mentation, and mobility). The onset of the Coronavirus (COVID-19) pandemic has led to new recommendations that were proposed concerning training by mental health professionals, social workers, nursing home administrators, and volunteers in order to deliver mental healthcare for persons living with dementia [36].

\subsection{Summit Second Theme: Improve Recruitment, Retention, and Job Quality}

Recommendation 2 of the 2020 Summit recommendations addresses job quality, recruitment, and retention of direct care workers (DCWs). DCWs, as the paid frontline of support for older adults and people with disabilities, are increasingly central to the well-being of persons living with dementia. Due to the growing number of older adults and the persistence of poor job quality in direct care, the long-term care sector will need to fill 8.2 million job openings in direct care between 2018 and 2020 [37]. Without a range of interventions that improve job quality, recruitment, and 
retention in this job sector, persons living with dementia will not receive the services and supports they need.

2020 Summit Recommendation 2: Identify and evaluate strategies to improve recruitment, retention, and job quality (e.g. specialty dementia training, career lattices, transferable credentials, and stackable education) among the direct care workforce.

A range of strategies can ensure an adequate supply of DCWs to meet demand. Workforce experts have identified the major drivers of turnover in this sector as low compensation, weak training standards, limited career advancement opportunities, weak data systems, and inadequate Medicaid reimbursement rates, among others [38]. Targeted interventions for these problems will boost recruitment and retention in this workforce, ensuring an adequate supply of workers to support persons living with dementia. Additionally, providing continuing education opportunities, and ensuring transferable credentials and stackable education for the direct care workforce would maximize workers across all long-term care settings and support their career growth [39].

Dementia-specific advanced roles can help build dementia care competence in direct care [40]. Dementia care training requirements can improve across the direct care workforce; currently this content is only mandated for nursing assistants at the federal level and for home care workers in 13 of the US states. An advanced specialty role in dementia care could also be developed for DCWs. This role would support persons living with dementia and their families and other caregivers by addressing behavioural triggers, aiding with care transitions, and communicating with all members of the interdisciplinary care team.

\subsection{Summit Third Theme: Technology, Evidence-Based Practices, Culturally Competent Care}

The Workgroup identified four recommendations related to technology; (1) engage the dementia care workforce needed to advance use of person-centred technologies; (2) translate and disseminate evidence-based dementia care practices; (3) strengthen and expand diversity and cultural competency of the dementia care workforce; and (4) determine the costs and benefits of having culturally competent person- and family-centred dementia care. Given current workforce needs and anticipated shortages as the U.S. population continues to age, there is a need for determining the efficacy of new and emerging technologies. These technologies may include computer-based applications, assistive robotic technologies, therapeutic technologies, smart home/home monitoring technologies, and smartphone applications [11, 41]. Research is needed to improve understanding of how person--centred technologies can enhance care coordination, promote self-care for persons living with dementia, support shared-decision making among persons living with dementia and their caregivers, and improve communication across the interdisciplinary care team. Each of the four research recommendations related to this theme $(2020$ Summit Recommendations 3, 4, 5, and 6) are discussed below.

2020 Summit Recommendation 3: Engage the dementia care workforce in the development and evaluation of person-centred technologies to build workforce capacity to support persons living with dementia.

Development and evaluation of person-centred technologies should consider the following design principles: (1) simplicity, (2) ease of use, (3) privacy protections, and (4) integration with other technologies such as the electronic health record. Technologies must be simple enough that persons living with dementia and their families can use them. Research in other areas of family and 
caregiver support technologies have demonstrated the need to ensure information systems are easy to use [42]. Also, protecting the privacy of persons living with dementia, particularly in the early stages of disease, should be included as part of data security and privacy. The use of technologies should be integrated with the information systems that support persons living with dementia, including enabling them to live independently and with dignity so that their voices are acknowledged.

2020 Summit Recommendation 4: Conduct implementation research that assesses barriers and effective strategies to translating and disseminating evidence-based practices for dementia care, services, technologies, and supports in education, policy, and practice.

The current dementia care workforce often lacks knowledge of, and access to, evidence-based practices for dementia care. Much of the current research has focused on training and education of the dementia care workforce [43]; however, additional research is needed to better understand how evidence-based practices and technologies from clinical settings can be disseminated, adopted, and translated into real-world, dementia care settings (e.g., home care, community-based supports and services, adult day services, assisted living, nursing homes, and other healthcare systems). There is a need for understanding how evidence-based behavioural interventions translate into supporting families and other caregivers in real-world settings. Finally, there is a need for research on the sustainability of these evidence-based practices [44]. This includes understanding how current payment models, such as Medicare Fee-for-Service plans fail to address care needs; and incorporating other payment models for care delivery, such as managed care models that cover the costs of evidence-based dementia care practices and technologies.

2020 Summit Recommendation 5: Identify barriers and effective strategies for expanding and strengthening a diverse and culturally competent dementia care workforce.

The prior two Summit research recommendations focused on improving cultural competency of the dementia care workforce and assessing its impact. This included enhancing the current and future diversity and cultural competency of the workforce. The Workgroup recommends a personcentred, cultural competency framework [45] that addresses: (1) experiences of persons living with dementia and caregivers; (2) their lived environment; and (3) their socio-cultural context. The sociocultural context includes attitudes, values, beliefs, and behaviours of cultures, as well as how these intersect with age, race, ethnicity, gender/gender identity, sexual orientation, and relationship to persons living with dementia, as well as account for educational background, social class, linguistics, religion, and other social and behavioural determinants of health [46, 47].

Cultural competency requires the collection of data that reflects the heterogeneity of Alzheimer's and related dementias. This may include evaluating the overlap between the prevalence of chronic disease in communities of colour and vulnerable populations, as well as the social and behavioural determinants that drive disparities in access, treatment, and continuity of dementia care. It may also include encouraging public agencies that collect data such as the U.S. Centers for Disease Control and Prevention (CDC), and U.S. national surveys such as the Behavioral Risk Factors Surveillance System (BRFSS), to identify demographic data on race and ethnicity that can be used to better understand the context of person- and family-centred care models.

2020 Summit Recommendation 6: Evaluate the short-term and long-term costs and benefits of interventions that prepare the healthcare workforce to provide culturally competent person- and family-centred dementia care. 
A better understanding of costs and benefits of having a culturally competent dementia care workforce, and the impact of cultural competency on the delivery of person- and family-centred dementia care will likely have important implications for health policy. The COVID-19 pandemic has raised numerous issues regarding health disparities that may put persons living with dementia at higher risk. Supportive interventions need to account for implicit and explicit bias that may result in inequitable treatment. The CDC has acknowledged that discrimination, lack of access to healthcare services, income and wealth gaps, and housing insecurity, among other factors, can drive health disparities in identifying and treating COVID-19 [48]. As researchers seek to understand what drives these health inequities and disseminate these findings through cultural competency training, further information quantifying the impact of disparities on real-time decision making and the benefits to the health system as well as improved care delivery could drive better outcomes for persons living with dementia, and their families and other caregivers.

\subsection{Summit Fourth Theme: Core Educational Competencies, Domains and Milestones}

In the U.S., persons living with dementia are high utilizers of healthcare [49]. They occupy a significant portion of hospital and skilled nursing facility beds, and receive care in the community through a patchwork of services, including primary and specialty care clinics, home and communitybased supports and services, and informal care [50]. The quality of life for persons living with dementia greatly depends on the adequacy of the knowledge and skills of the paid and unpaid caregivers that support them $[51,52]$. Basic and continuing education requirements for training are under-specified across the healthcare workforce specifically for unlicensed and frontline workforce [53-56]. Compounding the problem is the lack of knowledge and skills among the heath care workforce on how to optimize use of technology in education and practice. Four of the ten 2020 Summit recommendations relate to this theme (2020 Summit Recommendations 7, 8, 9, and 10).

2020 Summit Recommendation 7: Determine the core competencies, domains, and milestones needed to ensure that care is appropriate and maximizes function and quality of life for persons living with dementia and those who care for them.

The core competency, domain and milestone requirements for paid direct care providers, who deliver the majority of hands-on care, are neither clearly delineated nor required within the longterm care services and support industry. Studies underline the importance of minimum competencies in understanding dementia, person-centred care, communication and teamwork, dining and nutrition, prevention and reporting of abuse, empowering the person/meaningful engagement and palliative and end-of-life care [57-59]. Given that a significant number of persons living with dementia remain in their communities for many years, basic dementia-specific competencies, domains, and milestones should be developed for paid and unpaid caregivers, and training to achieve those competencies be made readily available. Further, beyond basic core competencies for paid and unpaid caregivers, there is a need to specify advanced, profession, role and/or occupation-specific competencies. This includes examining the linkages between organization-wide accrual of staff with these competencies to improved quality of life for persons living with dementia and their unpaid caregivers. Research is needed that elaborates and operationalizes these core competencies, domains and milestones; specifies the most effective education and training models to deliver the content; and describes the relationship between 
competency development and outcomes for persons living with dementia and their families and other caregivers.

2020 Summit Recommendation 8: Evaluate the effectiveness of competency-based training in technology use (e.g. apps, mobile devices, robotics, wearable technologies, data mining, telephonic support, etc.) among the dementia care workforce.

Advances in both consumer-focused and healthcare-focused technology hold the potential to improve the quality of life of persons living with dementia, by facilitating aging in place, promoting social engagement, and supporting autonomy [60]. Examples of such technology include: wearable devices that incorporate sensors and associated mobile applications to support assessment and monitoring of individuals to promote safety; assistive robotics and reminder applications to support independence in function; and therapeutic robots to promote wellbeing through stimulating reminiscence and by decreasing loneliness and anxiety [11].

Technology can also support caregivers [61]. For instance, during the COVID-19 pandemic, telehealth technology has become an essential part of care by linking persons living with dementia and their families and other caregivers to healthcare providers. Expanded use of technology also holds promise for enhancing the workforce's capacity to deliver person-centred care. Yet, currently, there is a lack of information on how best to prepare the workforce to use these technologies. Healthcare workers will need to learn when a specific technological solution is appropriate and when it is not, how to use the technology and ensure availability of technological supports, and how to monitor their use.

Examples of research addressing competency-based training in technology use that is needed to support successful implementation of recent technological advances in dementia care include examining: (1) the processes required to master implementation of new technology interfaces to support a person-centred care plan and how to deploy that technology among older adults who may struggle to learn new interfaces; (2) outcomes of technology on workforce member's wellbeing and retention in the workforce; (3) barriers that healthcare professionals of various levels experience with respect to integrating technology to deliver care that may require acquisition of new competencies, and how to overcome those barriers to equitably deliver care. Examples of barriers include the "digital divide" experienced by those in rural and low resource communities, and perceptions regarding the uses and misuse of technology in the management of dementia care. It should be remembered that technology is not meant to replace home care workers, since the nature of that work largely requires in-person support [62].

2020 Summit Recommendation 9: Identify the competencies for the healthcare workforce, including the dementia care workforce, to coordinate and facilitate care transitions with a goal to improve the delivery of dementia care and services, increase satisfaction with care, and reduce costs.

Skillful care coordination offered at an appropriate level of intensity can improve outcomes for persons living with dementia and their families and other caregivers, including reduced use of institutional care $[63,64]$. Care coordination should be person-centred, include sustained attention to the needs of informal caregivers, and include targeted referrals to community-based supports and services. Diverse payment models across care settings and specialties, and state-level variability regarding qualifications for dementia care coordinators present challenges in assuring baseline competency among care coordinators [64]. Moreover, the relatively low strength of evidence regarding care coordination interventions may delay widespread implementation of these promising interventions, particularly if basic qualifications for care coordination staff remain unclear 
[63]. Research to develop consensus around basic- and advanced-level qualifications for care coordination that also promotes effective care transitions would form the basis for pragmatic comparative effectiveness trials that could establish more definitively the competencies required for effective care coordination for persons living with dementia. Such studies should take into account how care coordination competencies may vary depending upon disease heterogeneity, the presence or absence of comorbid illness, and the effects of social drivers of health. In addition, research is essential to determine the most effective approaches to promoting cultural humility, teamwork, communication, interdisciplinary collaboration and healthy relationships among staff, residents and their families and other caregivers within and between workplaces, as well as emphasizing effective models of leadership development to promote these approaches [65]. Finally, examining system-level barriers to care transitions and coordinating across different points of care, with an emphasis on staff competencies is needed to address these barriers.

2020 Summit Recommendation 10: Examine the educational and training landscape of the healthcare workforce, including basic preparatory curricula and continuing education, to understand the effectiveness and gaps in culturally competent person- and family-centred dementia care.

The inclusion of dementia-specific, culturally appropriate, and person- and family-centred competency development into the basic and continuing education requirements across the healthcare workforce is sparse and variable despite pervasive perceived value of such competency development $[66,67]$. Given the enduring social inequalities systematically embedded in the U.S.'s healthcare system, it is vital that research address both the effectiveness of such training and its impact on organizational outcomes in addition to care quality, and the quality of life of persons living with dementia and their families and other caregivers. Rigorous studies of interprofessional education are needed to inform next steps to support the healthcare workforce to become culturally sensitive and competent in applying a lens of intersectionality [68] to provide person and family-centred care. Examples of these robust studies should involve education that includes staff empowerment at all levels of the healthcare workforce and amplifies the voices of persons living with dementia and their families and other caregivers. The aforementioned research is needed to build an evidence base from which to elaborate the basic and continuing education requirements (e.g. topics, modalities, competency development) across the healthcare workforce [69]. Finally, rigorous translation and implementation research on the effectiveness of such training is also needed.

\section{Discussion}

The 2020 Summit research recommendations presented here were developed to improve care for all persons living with dementia, including those with advanced dementia, and their families and other caregivers in the U.S. However, the Workgroup feels that these recommendations have validity in other countries as well. These research recommendations, which address the four main themes of accountability by evaluating progress towards addressing the 2017 Summit workforce recommendations; improving job quality, recruitment, and retention of direct care workers (DCWs); creating a tech-savvy and culturally competent workforce; and developing educational core competencies, domains and milestones, represent topics that are of world-wide concern and will result in the development of evidence-based practices for workforce development. Entities that are 
accountable for promoting dementia care workforce development are well positioned to engage multiple partners to further advance the knowledge and skills of providers across the educational continuum. Dementia care, especially in the advanced stages, can be both exhausting and rewarding; and as the average ages of the world's populations increase, more providers, both formal and informal, trained and volunteer, will need to be recruited, trained, and retained. Strategies must be identified and/or created to improve job satisfaction for this often challenging task of caring for persons living with advanced dementia. Technology, evidence-based practices, and culturally competent care are all tools that, if used properly, will ease the burden of care and maintain quality of life for both persons living with advanced dementia and their families and other caregivers. Finally, the creation of universal dementia competencies, domains, and milestones will facilitate both the uniform training of providers and caregivers and the adoption of new tools as they become available. In addition, the level of job satisfaction will likely increase as identified competencies, domains and milestones are reached, exceeded and used to redefine exceptional care for persons living with advanced dementia and those who care for them.

\section{Conclusions}

Healthcare providers and family members and other caregivers must be prepared to provide quality care and ensure the safety of those who live with dementia. These 2020 Summit research recommendations are offered for consideration by each of these groups who provide care for persons living with dementia. The goal of appropriate dementia care is to acknowledge what matters most to persons living with dementia and to provide person-centred care. Healthcare professionals, family members and other caregivers must be trained to embrace the choices made by persons living with dementia to the best of their abilities. The Workgroup offers these 2020 Summit research recommendations as a step towards identifying ways to promote safe care and respectful options for persons in all stages of their dementia journey. The goal of these recommendations is to translate research into the tools that can be used in education and practice and thereby influence policy.

\section{Acknowledgments}

The authors would like to extend a special thanks to Roy Thompson, PhD candidate, at the School of Nursing at Duke University for his expert assistance during the development of the competency recommendations.

\section{Author Contributions}

Drs. Weiss and Tumosa and Mr. Espinoza served as co-chairs on the 2020 Workforce Development Workgroup. Drs. Bragg, Craft Morgan, Flatt, and McConnell and Ms. Whiting served as Workgroup members. All authors participated in writing the manuscript.

\section{Competing Interests}

The authors have declared that no competing interests exist. 


\section{References}

1. National Institute on Aging. Summit virtual meeting series: 2020 national research summit on care, services, and supports for persons with dementia and their caregivers [Internet]. Washington, DC: US Department of Health and Human Services. Available from: https://www.nia.nih.gov/2020-dementia-care-summit.

2. ASPE: Office for the Assistant Secretary for Planning and Evaluation. Workforce gaps in dementia education and training [Internet]. Washington: US Department of Health and Human Services; 2017. Available from: https://aspe.hhs.gov/pdf-report/workforce-gaps-dementia-educationand-training.

3. Weiss J, Tumosa N, Perweiler E, Forciea MA, Miles T, Blackwell E, et al. Critical workforce gaps in dementia education and training. J Am Geriatr Soc. 2020; 68: 625-629.

4. ASPE: Office for the Assistant Secretary for Planning and Evaluation. 2020 Workforce development recommendations [Internet]. Washington: US Department of Health and Human Services; $2020 . \quad$ Available from: https://aspe.hhs.gov/system/files/pdf/263856/WorkforceRecom20.pdf.

5. Fazio S, Pace D, Maslow K, Zimmerman S, Kallmyer B. Alzheimer's association dementia care practice recommendations. Gerontologist. 2018; 58: S1-S9.

6. Super N. "Who will be there to care? The growing gap between caregiver supply and demand [Internet]." Washington, DC: National Health Policy Forum; 2002. Available from: https://hsrc.himmelfarb.gwu.edu/sphhs centers nhpf/89.

7. AARP and National Alliance for Caregiving. Caregiving in the United States [Internet]. Washington, DC: AARP; 2020. Available from: https://www.caregiving.org/wpcontent/uploads/2020/06/AARP1316_RPT CaregivingintheUS WEB.pdf.

8. Siconolfi D, Shih RA, Friedman EM, Kotzias VI, Ahluwalia SC, Phillips JL, et al. Rural-urban disparities in access to home-and community-based services and supports: Stakeholder perspectives from 14 states. J Am Med Dir Assoc. 2019; 20: 503-508.e1.

9. Lorenz K, Freddolino PP, Comas-Herrera A, Knapp M, Damant J. Technology-based tools and services for people with dementia and carers: Mapping technology onto the dementia care pathway. Dementia. 2019; 18: 725-741.

10. Astell AJ, Bouranis N, Hoey J, Lindauer A, Mihailidis A, Nugent C, et al. Technology and dementia: The future is now. Dement Geriatr Cogn Disord. 2019; 47: 131-139.

11. Moyle W. The promise of technology in the future of dementia care. Nat Rev Neurol. 2019; 15: 353-359.

12. Ballard C, Corbett A, Orrell M, Williams G, Moniz-Cook E, Romeo R, et al. Impact of personcentred care training and person-centred activities on quality of life, agitation, and antipsychotic use in people with dementia living in nursing homes: A cluster-randomised controlled trial. PLoS Med. 2018; 15: e1002500.

13. Surr CA, Holloway I, Walwyn RE, Griffiths AW, Meads D, Kelley R, et al. Dementia Care Mapping ${ }^{\mathrm{TM}}$ to reduce agitation in care home residents with dementia: The EPIC cluster RCT. Health Technol Assess. 2020; 24: 1-172.

14. Brodaty $\mathrm{H}$, Peters KE. Cost effectiveness of a training program for dementia carers. Int Psychogeriatr. 1991; 3: 11-22.

15. Gitlin LN, Hodgson N, Jutkowitz E, Pizzi L. The cost-effectiveness of a nonpharmacologic 
intervention for individuals with dementia and family caregivers: The tailored activity program. Am J Geriatr Psychiatry. 2010; 18: 510-519.

16. Hirschman KB, Hodgson NA. Evidence-based interventions for transitions in care for individuals living with dementia. Gerontologist. 2018; 58: S129-S140.

17. Callahan CM, Boustani MA, Weiner M, Beck RA, Livin LR, Kellams JJ, et al. Implementing dementia care models in primary care settings: The aging brain care medical home. Aging Ment Health. 2011; 15: 5-12.

18. Reuben DB, Evertson LC, Wenger NS, Serrano K, Chodosh J, Ercoli L, et al. The university of California at Los Angeles Alzheimer's and dementia care program for comprehensive, coordinated, patient-centered care: Preliminary data. J Am Geriatr Soc. 2013; 61: 2214-2218.

19. Bass DM, Judge KS, Lynn Snow A, Wilson NL, Morgan R, Looman WJ, et al. Caregiver outcomes of partners in dementia care: Effect of a care coordination program for veterans with dementia and their family members and friends. J Am Geriatr Soc. 2013; 61: 1377-1386.

20. Bass DM, Judge KS, Snow A, Wilson NL, Morgan RO, Maslow K, et al. A controlled trial of partners in dementia care: Veteran outcomes after six and twelve months. Alzheimer's Res Ther. 2014; 6: 9.

21. American Association of Colleges of Nursing. The essentials of baccalaureate education for professional nursing practice [Internet]. Washington, DC: American Association of Colleges of Nursing; $2008 . \quad$ Available from: https://www.aacnnursing.org/Portals/42/Publications/BaccEssentials08.pdf.

22. American Association of Colleges of Nursing. DRAFT the essentials: Core competencies for professional nursing education [Internet]. Washington, DC: American Association of Colleges of Nursing; $2020 . \quad$ Available from: https://www.aacnnursing.org/Portals/42/Downloads/Essentials/Essentials-Draft-Document10-20.pdf.

23. Obeso V, Brown D, Aiyer M, Barron B, Bull J, Carter T, et al. Core entrustable professional activities for entering residency: Toolkits for the 13 core EPAs [Internet]. Washington, DC: Association of American Medical Colleges; 2017. Available from: https://www.aamc.org/system/files/c/2/482214-epa13toolkit.pdf.

24. Accreditation Council for Graduate Medical Education. Common program requirements (residency). Chicago, IL: Accreditation Council for Graduate Medical Education; 2020. Available from:

https://www.acgme.org/Portals/O/PFAssets/ProgramRequirements/CPRResidency2020.pdf.

25. Commission on Accreditation in Physical Therapy Education. Standards and Required elements for accreditation of physical therapist education programs 2020 [Internet]. Alexandria, VA: Commission on Accreditation in Physical Therapy Education; 2020. Available from: http://www.capteonline.org/uploadedFiles/CAPTEorg/About CAPTE/Resources/Accreditation Handbook/CAPTE PTStandardsEvidence.pdf.

26. Accreditation Council for Occupational Therapy Education. Standards and Interpretive Guide [Internet]. North Bethesda, MD: Accreditation Council for Occupational Therapy Education; 2018. Available from: https://acoteonline.org/accreditation-explained/standards/.

27. Council on Social Work Education, Commission on Educational Policy, \& Commission on Accreditation. 2015 educational policy and accreditation standards for baccalaureate and master's social work programs [Internet]. Alexandria, VA: Council on Social Work Education, 
Commission on Educational Policy, \& Commission on Accreditation; 2015. Available from: https://www.cswe.org/getattachment/Accreditation/Standards-and-Policies/2015EPAS/2015EPASandGlossary.pdf.aspx.

28. Commission on Accreditation, American Psychological Association. Standards for accreditation for health service psychology and accreditation operating procedures [Internet]. Washington, DC: Commission on Accreditation, American Psychological Association; 2018. Available from: https://www.apa.org/ed/accreditation/about/policies/standards-of-accreditation.pdf.

29. Accreditation Council for Nutrition Professional Education. Handbook of accreditation for master's degree clinical programs in advanced nutrition [Internet]. New York, NY: Accreditation Council for Nutrition Professional Education; 2019. Available from: https://acnpe.org/sites/default/files/attachments/ACNPE\%20Handbook\%20of\%20Accreditati on\%20-\%20Revised\%20July\%202019\%20-\%20Final.pdf.

30. Accreditation Review Commission on Education for the Physician Assistant. Accreditation standards for physician assistant education [Internet]. Johns Creek, GA: Accreditation Review Commission on Education for the Physician Assistant; 2020. Available from: http://www.arcpa.org/wp-content/uploads/2020/12/Standards-5th-Ed-Sept-2020.pdf.

31. Commission on Dental Accreditation. Accreditation standards for dental hygiene education programs [Internet]. Chicago, IL: Commission on Dental Accreditation; 2019. Available from: https://www.ada.org/ /media/CODA/Files/dental hygiene standards.pdf?la=en.

32. Commission on Dental Accreditation. Accreditation standards for dental education programs [Internet]. Chicago, IL: Commission on Dental Accreditation; 2019. Available from: https://www.ada.org/ /media/CODA/Files/predoc standards.pdf?la=en.

33. Brodaty $\mathrm{H}, \mathrm{Green} \mathrm{A}$, Koschera A. Meta-analysis of psychosocial interventions for caregivers of people with dementia. J Am Geriatr Soc. 2003; 51: 657-664.

34. Semiatin AM, O'Connor MK. The relationship between self-efficacy and positive aspects of caregiving in Alzheimer's disease caregivers. Aging Ment Health. 2012; 16: 683-688.

35. De Biasi A, Wolfe M, Carmody J, Fulmer T, Auerbach J. Creating an age-friendly public health system. Innov Aging. 2020; 4: igz044.

36. Wang H, Li T, Barbarino P, Gauthier S, Brodaty H, Molinuevo JL, et al. Dementia care during COVID-19. Lancet. 2020; 395: 1190-1191.

37. PHI. Direct care workers in the United States: Key facts [Internet]. Bronx, NY: PHI; 2020. Available from: https://phinational.org/resource/direct-care-workers-in-the-united-states-key-facts/.

38. Espinoza R. Workforce matters: The direct care workforce and state-based LTSS Social insurance programs [Internet]. Bronx, NY: PHI; 2019. Available from http://phinational.org/resource/workforce-matters/.

39. Drake A. Direct care work is real work: Elevating the role of the direct care worker [Internet]. Bronx, NY: PHI; 2020. Available from: https://phinational.org/resource/direct-care-work-is-realwork-elevating-the-role-of-the-direct-care-worker/.

40. Scales K. "It's time to build dementia care competency in direct care [Internet]." Bronx, NY: PHI Blog; 2019. Available from: https://phinational.org/its-time-to-build-dementia-carecompetency-in-direct-care/.

41. Neal I, du Toit SH, Lovarini M. The use of technology to promote meaningful engagement for adults with dementia in residential aged care: A scoping review. Int Psychogeriatr. 2020; 32: 913935. 
42. Henoch I, Strang S, Larnebratt C, Hermansson J. Digital health support-a good thing, but not for me. Experiences of family caregivers and healthcare staff. Br J Guid Counc. 2020: 48: 1-12.

43. Lourida I, Abbott RA, Rogers M, Lang IA, Stein K, Kent B, et al. Dissemination and implementation research in dementia care: A systematic scoping review and evidence map. BMC Geriatr. 2017; 17: 147.

44. Gitlin LN, Baier RR, Jutkowitz E, Baker ZG, Gustavson AM, Sefcik JS, et al. Dissemination and implementation of evidence-based dementia care using embedded pragmatic trials. J Am Geriatr Soc. 2020; 68: S28-S36.

45. O'Connor D, Phinney A, Smith A, Small J, Purves B, Perry J, et al. Personhood in dementia care: Developing a research agenda for broadening the vision. Dementia. 2007; 6: 121-142.

46. Brooke J, Cronin C, Stiell M, Ojo O. The intersection of culture in the provision of dementia care: A systematic review. J Clin Nurs. 2018; 27: 3241-3253.

47. Dilworth-Anderson $\mathrm{P}$, Moon $\mathrm{H}$, Aranda MP. Dementia caregiving research: Expanding and reframing the lens of diversity, inclusivity, and intersectionality. Gerontologist. 2020; 60: 797805.

48. Centers for Disease Control and Prevention. "Health equity considerations and racial and ethnic minority groups [Internet]." Atlanta, GA: National Center for Immunization and Respiratory Diseases; 2021. Available from: https://www.cdc.gov/coronavirus/2019ncov/community/health-equity/race-ethnicity.html.

49. Lin PJ, Zhong Y, Fillit HM, Chen E, Neumann PJ. Medicare expenditures of individuals with Alzheimer's disease and related dementias or mild cognitive impairment before and after diagnosis. J Am Geriatr Soc. 2016; 64: 1549-1557.

50. Alzheimer's Association. 2015 Alzheimer's Disease facts and figures [Internet]. Chicago, IL: Alzheimer's \& Dementia; 2015. Available from: https://www.alz.org/media/documents/2015factsandfigures.pdf.

51. Jansen BD, Brazil K, Passmore P, Buchanan H, Maxwell D, Mcllfatrick SJ, et al. Exploring healthcare assistants' role and experience in pain assessment and management for people with advanced dementia towards the end of life: A qualitative study. BMC Palliat Care. 2017; 16: 6.

52. Surr CA, Gates C, Irving D, Oyebode J, Smith SJ, Parveen S, et al. Effective dementia education and training for the health and social care workforce: A systematic review of the literature. Rev Educ Res. 2017; 87: 966-1002.

53. Kelly CM, Morgan JC, Jason KJ. Home care workers: Interstate differences in training requirements and their implications for quality. J Appl Gerontol. 2013; 32: 804-832.

54. Kelly C, Craft Morgan J, Kemp CL, Deichert J. A profile of the assisted living direct care workforce in the United States. J Appl Gerontol. 2020; 39: 16-27.

55. Tyler DA, Jung HY, Feng Z, Mor V. Prevalence of nursing assistant training and certification programs within nursing homes, 1997-2007. Gerontologist. 2010; 50: 550-555.

56. Winchester L, Bercaw L. Improving the direct care workforce through core competency training. 2016. Doi: $10.13028 /$ n53t-1b29.

57. Fazio S, Pace D, Flinner J, Kallmyer B. The fundamentals of person-centered care for individuals with dementia. Gerontologist. 2018; 58: S10-S19.

58. Georgia Alzheimer's and Related Dementias Collaborative (GARD). Collaborative competency guide for dementia care: Direct care worker workforce development [Internet]. 2018. Available from:https://aging.georgia.gov/sites/aging.georgia.gov/files/GARD\%20Competency\%20Guide 
PDF.pdf.

59. Rycroft-Malone J, Burton C, Williams L, Edwards S, Fisher D, Hall B, et al. Improving skills and care standards in the support workforce for older people: A realist synthesis of workforce development interventions. Health Serv Deliv Res. 2016; 4. Doi: 10.3310/hsdr04120.

60. Samus QM, Black BS, Bovenkamp D, Buckley M, Callahan C, Davis K, et al. Home is where the future is: The BrightFocus foundation consensus panel on dementia care. Alzheimers Dement. 2018; 14: 104-114.

61. Williams KN, Perkhounkova Y, Shaw CA, Hein M, Vidoni ED, Coleman CK. Supporting family caregivers with technology for dementia home care: A randomized controlled trial. Innov Aging. 2019; 3: igz037.

62. Scales K. Leveraging technology to support-not supplant-the home care workforce [Internet]. Bethesda, Ma: Health Affairs; 2019. Available from: https://www.healthaffairs.org/do/10.1377/hblog20190805.54553/full/.

63. Butler M, Gaugler JE, Talley KMC, Abdi HI, Desai PJ, Duval S, et al. Care interventions for people living with dementia and their caregivers. Rockville, MD: Agency for Healthcare Research and Quality; 2020; No. 20-EHCO23.

64. Hollister B, Flatt JD, Chapman SA. Dementia-capable care coordination in duals demonstration programs: Workforce needs, promising practices, and policy. Gerontologist. 2018; 58: 768-778.

65. Gilster SD, Boltz M, Dalessandro JL. Long-term care workforce issues: Practice principles for quality dementia care. Gerontologist. 2018; 58: S103-S113.

66. Brownie S, Nancarrow S. Effects of person-centered care on residents and staff in aged-care facilities: A systematic review. Clin Interv Aging. 2013; 8: 1-10.

67. Truong $M$, Paradies $Y$, Priest $N$. Interventions to improve cultural competency in healthcare: $A$ systematic review of reviews. BMC Health Serv Res. 2014; 14: 99.

68. Carbado DW, Crenshaw KW, Mays VM, Tomlinson B. INTERSECTIONALITY: Mapping the movements of a theory1. Du Bois Rev. 2013; 10: 303-312.

69. Reeves S, Perrier L, Goldman J, Freeth D, Zwarenstein M. Interprofessional education: Effects on professional practice and healthcare outcomes. Cochrane Database Syst Rev. 2013; 2013: CD002213.

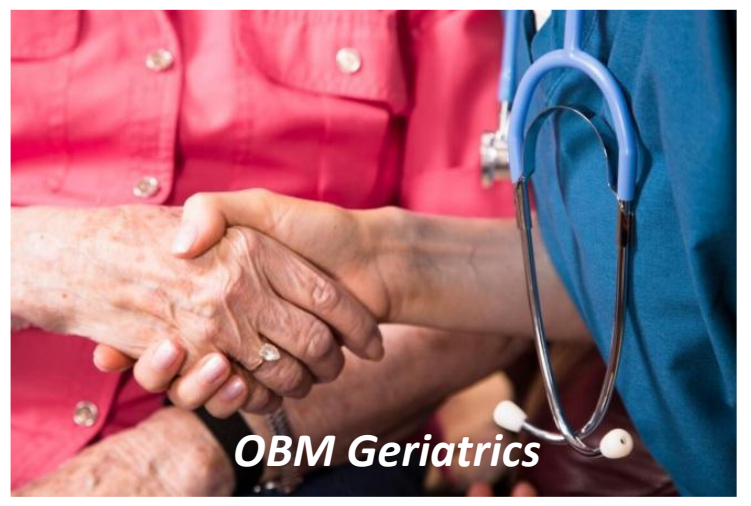

Enjoy $O B M$ Geriatrics by:

1. Submitting a manuscript

2. Joining in volunteer reviewer bank

3. Joining Editorial Board

4. Guest editing a special issue

For more details, please visit: http://www.lidsen.com/journals/geriatrics 